\title{
The effects of aqueous extract of Origanum vulgare on learning and memory in male rats
}

\author{
Ahvan Ghaderi $^{1^{\circledR}}$, Seyed Asaad Karimi ${ }^{1,2}{ }^{\circledR}$, Fahimeh Talaei $^{(\mathbb{D}}$, Siamak Shahidi $^{1,2}{ }^{\circledR}$, Nafiseh Faraji $^{\circledR}$, Alireza $^{\circledR}$ \\ Komaki $^{1,2 *}$ \\ ${ }^{1}$ Neurophysiology Research Center, Hamadan University of Medical Sciences, Hamadan, Iran \\ ${ }^{2}$ Department of Neuroscience, School of Advanced Technologies in Medicine, Hamadan University of Medical Sciences, Hamadan, Iran
}

\section{A R T I C L E I N F O}

Article Type:

Original Article

\section{Article History:}

Received: 24 October 2019

Accepted: 26 January 2020

\section{Keywords:}

Medicinal plant

Avoidance learning

Origanum vulgare

Anti-oxidants

Locomotor activity

\begin{abstract}
A B S T R A C T
Introduction: The effectiveness of antioxidants on learning and memory improvement has been shown, previously. Due to the high level of antioxidants, available in Origanum vulgare, the present experiment aimed to examine the effect of aqueous extract of $O$. vulgare on passive avoidance learning (PAL) in male Wistar rats.

Methods: This study was performed on 30 male Wistar rats weighing 250 to 290 g. The rats were randomly assigned into five groups $(\mathrm{n}=6)$, as follows: the control, sham (saline), and three groups treated with different doses of $O$. vulgare extract $(150,250$, and $350 \mathrm{mg} / \mathrm{kg}$ ). The saline or extract was administered via daily oral gavage for 14 days. The groups were then subjected to the passive avoidance task, and their behaviors were recorded. The rats' locomotor activity was also measured using the open field test.

Results: The number of trials to acquisition was significantly lower in the "O. vulgare (350 mg/ $\mathrm{kg}$ )" group than the control group. The step-through latency and the time spent in the dark compartment in the retention test, was significantly higher and lower in the "O. vulgare (250 and $350 \mathrm{mg} / \mathrm{kg}$ )" groups than the control group, respectively. No significant differences were found in the distances traveled among the experimental groups in the open field test.

Conclusion: Aqueous extract of $O$. vulgare can enhance learning and memory. The high levels of antioxidants in O. vulgare extract may be responsible for its effectiveness in learning and memory.
\end{abstract}

Implication for health policy/practice/research/medical education:

The results of this study showed that the aqueous extract of Origanum vulgare enhanced learning and memory in rats. Hence, this plant might be useful in patients with Alzheimer's disease. One of the mechanisms underlying the effectiveness of $O$. vulgare on learning and memory may be related to its antioxidant properties.

Please cite this paper as: Ghaderi A, Karimi SA, Talaei F, Shahidi S, Faraji N, Komaki A. The effects of aqueous extract of Origanum vulgare on learning and memory in male rats. J Herbmed Pharmacol. 2020;9(3):239-244. doi: 10.34172/jhp.2020.31.

\section{Introduction}

Plant extracts are attractive candidates for treating brain function abnormalities and metabolic disorders of individuals with specific pathological conditions, which is due to their inherent antioxidant property as well as beneficial effects on human health (1-3).

Origanum vulgare is native to Europe, Northern Africa, America, and Asia (4) and is widely distributed in these regions. It is commonly used as a spice in many diets and also as a therapeutic agent for several diseases, including colds, coughs, and digestive disorders (5). In addition, $O$. vulgare is rich in phenol and ester compounds (1) and also exerts strong antimicrobial and antioxidant activities
(6). The high levels of carvacrol, flavonoid, and phenolic acid contents of $O$. vulgare $(7,8)$ are responsible for its antioxidant activity (9-11). Moreover, these phenolic antioxidants have diverse biological activities, as they exhibit anti-ulcer, anti-inflammatory, antidiabetic, antiviral, cytotoxic, and antitumor effects (12), and are also associated with the health benefits of $O$. vulgare.

Indeed, the antioxidants derived from natural sources have recently been regarded, since different forms of active oxygen are thought to be harmful to human health. In particular, the aqueous extract of $O$. vulgare is known to have antioxidant activity (13). Rosmarinic acid, eriocitrin, apigenin-7-O-glucoside, and oreganol are the most 
important bioactive constituents in O. vulgare $(14,15)$.

An important characteristic of animals and humans is the ability to alter their behavior based on experience, owing to their learning and memory capabilities. Learning is the acquisition of a skill or knowledge, whereas memory is the maintenance and storage of information. Learning and memory are closely related concepts and should not be considered separately $(16,17)$. Learning and memory are regarded as the most important functional levels of the central nervous system, as they are involved in encoding, storing, retaining, and recalling information (18).

Many recent studies have focused on the role of medicinal plants in learning and memory. Therefore, this study was conducted to evaluate the effects of the aqueous extract of $O$. vulgare on passive avoidance learning (PAL).

\section{Materials and Methods}

Animals

Thirty male Wistar rats weighing 250 to $290 \mathrm{~g}$ were prepared from the Hamadan University of Medical Sciences. The animals were housed in a temperaturecontrolled room with a 12-hour light-dark cycle.

\section{Preparation of O. vulgare extract}

Origanum vulgare leaves were collected in the spring from Sanandaj, Kurdistan, Iran. The leaves were dehydrated and powdered. Then, the powder was refluxed with distilled hot water $\left(<50^{\circ} \mathrm{C}\right)$ by a ratio of $1 / 100$ for a full day. The solution was filtered using a filter paper, and after reducing the pressure by a Rotary evaporator $\left(40^{\circ} \mathrm{C}\right)$, the compound was condensed. Evaporation yielded a semisolid mass. A stock suspension of the mixture was made by dissolving $5 \mathrm{~g}$ of the compound in $100 \mathrm{~mL}$ of distilled water to achieve a solution with a concentration of $50 \mathrm{mg} /$ $\mathrm{mL}$. Other concentrations were prepared from this stock suspension by diluting this solution with an appropriate amount of distilled water (19).

\section{Experimental design}

The animals (30 rats) were separated into five groups ( $\mathrm{n}$ $=6$ per group), as follows: the control, sham (saline), and three groups treated with different doses of the O. vulgare extract $(150,250$, and $350 \mathrm{mg} / \mathrm{kg})$. The saline or O. vulgare extract was administered once a day (at about 08:00 AM) for 14 days by oral gavage. The experimental timeline is shown in Figure 1.

\section{Open field test}

Locomotor activity was assessed by an open field test, which was designed to measure behavioral responses, including locomotor and exploratory behaviors (20). The test apparatus consisted of a clear, square-shaped, plexiglas box $(76 \times 76 \mathrm{~cm})$ enclosed by 42 -cm-high matte walls, and its bottom consisted of 25 equal parts. For animal locomotion analysis, the rats were removed from their cages and located in the middle of the open field apparatus (one at a time). The area was entirely restricted by a white curtain to reduce extra-maze cues. On the test day, the caged rats remained in the experimental room for 30 minutes, and then each rat was placed in the middle of the apparatus, and the needed data were immediately recorded. To examine possible effects of the extract on locomotor activity, the total distance traveled $(\mathrm{cm})$ during 10 minutes of the test period was measured using a Maze Router (21).

Passive avoidance task

Step-through passive avoidance task

We used the step-through passive avoidance task to evaluate PAL and memory (22-25). The shuttle box apparatus consisted of a light compartment $(20 \times 20 \times 30 \mathrm{~cm})$ made of transparent plastic and a black compartment made of black opaque plastic $(20 \times 20 \times 30 \mathrm{~cm})$. The bottom of both compartments consisted of stainless steel rods $3 \mathrm{~mm}$ in diameter spaced by a distance of $1 \mathrm{~cm}$. A shock generator (Behbood Pardaz Co., Iran) electrified the floor of the black compartment. There was a rectangular opening (6 $\times 8 \mathrm{~cm}$ ) between the light and black compartment, which was closed by a matte guillotine door.

\section{Passive avoidance training}

The procedure was performed as described previously (25-28). In brief, after the rat entered the black chamber unconsciously (step-through latency, STLa), an electric shock was applied, and the animal was returned to its cage after 30 seconds. This procedure was repeated after 2 minutes. Each time the rat reentered the black compartment, a shock was applied. The training was finished, when the animal stayed in the light compartment for 120 continuous seconds (25-27). The number of trials to acquisition (NTa; entries into the black compartment) was noted.

The rats that did not cross into the black chamber

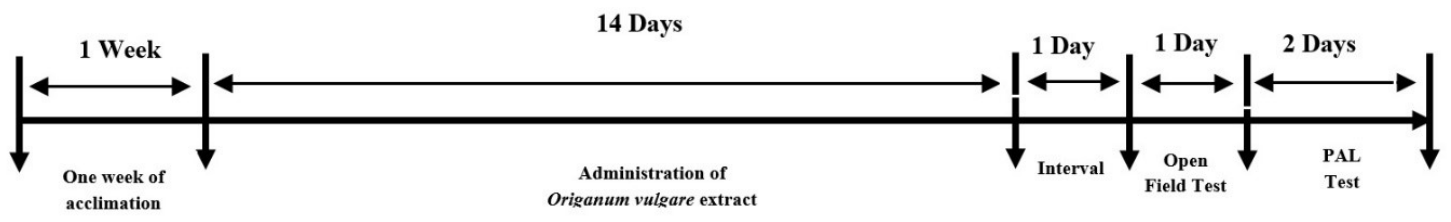

Figure 1. The experimental timeline. Following 14 days of $O$. vulgare extract administration in the experimental groups, the open field, and passive avoidance learning tests were performed. 
during the training period, except for the practice during the adaptation phase, were excluded from the experiment. A 3-second shock was delivered after 2 minutes, only if the same animal entered the black chamber following the first foot shock. The animals were immediately removed from the black compartment and transferred to their cages $(29,30)$.

\section{Retention test}

Twenty-four hours after training, the trained rats were subjected to the retention test with the same experimental procedure; however, no shock was applied to the grid floor after entering the animals to the black compartment $(31,32)$. During the retention test, the animals were allowed to access the black compartment for an ultimate time of 600 seconds. In this phase, the latency to enter the black compartment or STLr and the time spent in the black compartment (TDC) over a 10-minute cycle were recorded.

\section{Data analysis}

Statistical analyses were performed using the SPSS software. One-way analysis of variance (ANOVA) was used for multiple comparisons, followed by the Tukey's test. Values are expressed as mean \pm SEM, and the significance level was considered at 0.05 .

\section{Results}

Effects of $O$. vulgare on body weight

Although the rats' body weight increased during the experiment in all groups, the O. vulgare extract did not have a significant effect on the body weight of the subjects compared with the control group (Figure 2).

\section{Effects of O. vulgare on locomotor activity}

An open field test was used to assess motor activity as a reaction to an unknown environment. Figure 3 shows the total distance traveled (in centimeters) during the open field test in all experimental groups. No significant differences were observed in the distance traveled among

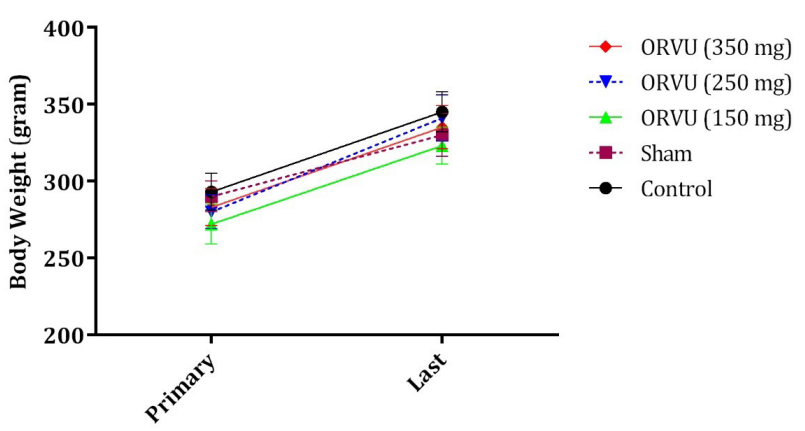

Figure 2. Effects of the aqueous extract of Origanum vulgare (ORVU) on the first and last body weight measurements in all experimental groups. Each column and bar represents the mean \pm SEM. the experimental groups $(P>0.05)$, which indicates that the locomotor activity and exploratory action of the rats in all groups were not differentiable.

Effects of $O$. vulgare on acquisition in the passive avoidance task

No significant difference was found in the STLa between the studied groups $(P=0.6716)$. This observation showed that the exploratory behavior of the animals in the black compartment was not differentiable. A significant difference was observed in the NTa between the groups (Figure 4). Specifically, the NTa in the "O. vulgare (350 $\mathrm{mg}$ )" group was significantly lower than that of the saline group $(P<0.05)$.

Effects of $O$. vulgare on retention in the passive avoidance task

Twenty-four hours after training, the retention test was performed. There were significant differences in the STLr between the studied groups (Figure 5A). The STLr values in the "O. vulgare (350 mg)" and "O. vulgare (250 $\mathrm{mg})$ " groups were significantly higher than the control

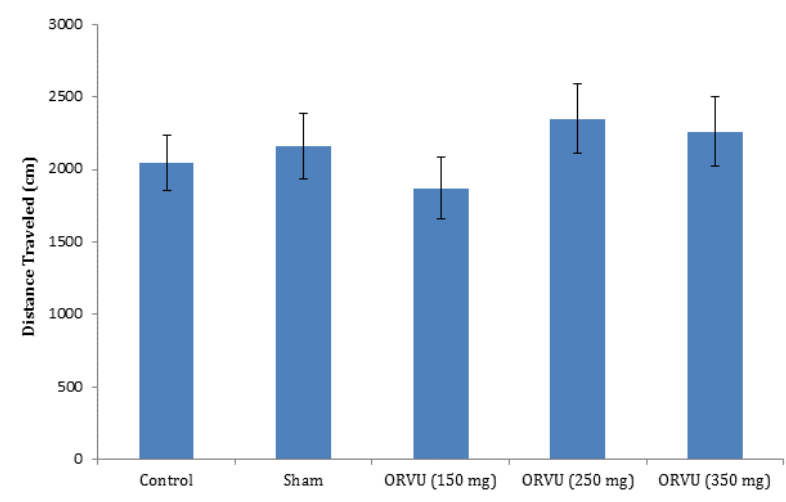

Figure 3. Effects of aqueous extract of Origanum vulgare (ORVU) on the total distance traveled in the open field test in all experimental groups. Each column and bar represents the mean \pm SEM. No significant differences were observed among the studied groups.

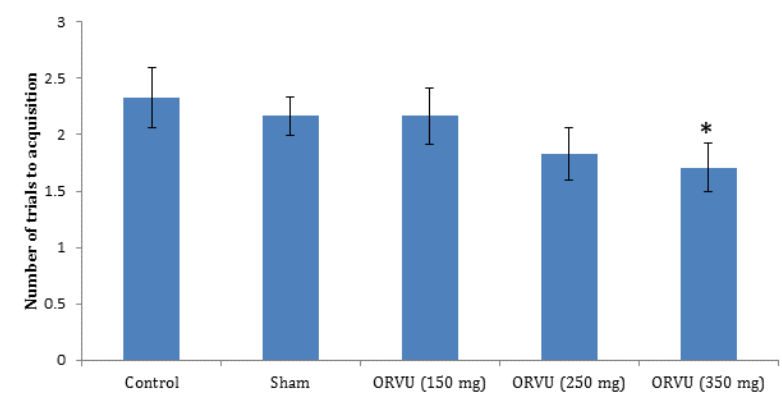

Figure 4. Effects of aqueous extract of Origanum vulgare (ORVU) on the number of trials to acquisition during the passive avoidance learning task in all groups. Each bar represents the mean \pm SEM. ${ }^{*} P<0.05$ compared with the control group. 
animals $(P<0.05)$. In addition, a significant difference was found in the time spent in the dark compartment among the groups (Figure 5B). The time spent in the dark compartment in the "O. vulgare (350 mg)" and " $O$. vulgare $(250 \mathrm{mg})$ " groups was significantly lower than that of the control group $(P<0.01)$. The time spent in the dark compartment in the "O. vulgare (350 mg)" group was significantly lower than that of the "O. vulgare $(150 \mathrm{mg})$ " group $(P<0.0001)$.

\section{Discussion}

The present study investigated the effects of aqueous extract of $O$. vulgare on learning and memory in male rats. Our results demonstrated that the aqueous extract of $O$. vulgare had a significant effect on learning and memory using a passive avoidance task. The O. vulgare-induced reduction in the $\mathrm{NTa}$ in the passive avoidance task demonstrated an increase in the acquisition. Moreover, an enhancement in the STLr and a reduction in the TDC in the $O$. vulgare groups during the retention test indicated the effectiveness of $O$. vulgare on memory retention $(24,33,34)$. Interestingly, no significant difference was found in the distance traveled among the experimental groups in the open field test, which demonstrated that the locomotor activity and exploratory behavior of the animals were not changed among the groups. In general, the aqueous extract of $O$. vulgare $(250$ and $350 \mathrm{mg} /$ $\mathrm{kg}$ ) increased PAL in comparison to the control group. However, no significant effects were found on the body weight, locomotion, and exploratory behavior of the animals.

Medicinal plants have been consumed by human beings to treat several disorders, such as pediatric diseases, neurological dysfunctions, pain, digestive disorders, hormonal imbalances, etc $(35,36)$. The role of medicinal plants and their extracts in cognitive function has recently been considered by many scientists (29). O. vulgare, Ficus carica, Melissa officinalis, Silybum marianum, Glycine max, Nigella sativa, Cannabis sativa, Rosmarinus officinale, and Boswellia spp. are some of the medicinal plants native to Iran, which have been used to improve memory and learning (37). Indeed, a previous study demonstrated that the consumption of $O$. vulgare extract improved discrimination learning and also the long-term potentiation induction and maintenance in the CA1 area of the hippocampus in rats (38). Moreover, intrahippocampal administration of aqueous extract of $O$. vulgare $(0.3,0.03$, and $0.003 \mu \mathrm{g} / \mathrm{kg})$ can decrease the total distance traveled and the time needed to find the hidden platform in the Morris Water Maze during training (39).

The mechanisms of action of $O$. vulgare are not fully understood. A recent study revealed that cognitive functions are impaired after oxidative stress, and oxidative stress contributes to cognitive impairment following oxidative brain damage (40). Furthermore,

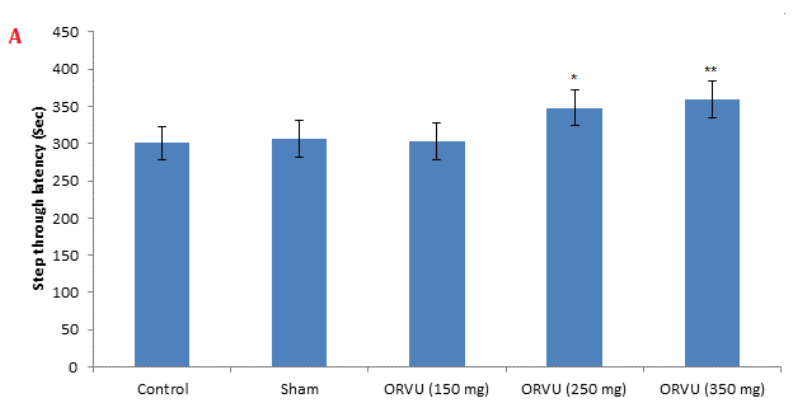

B

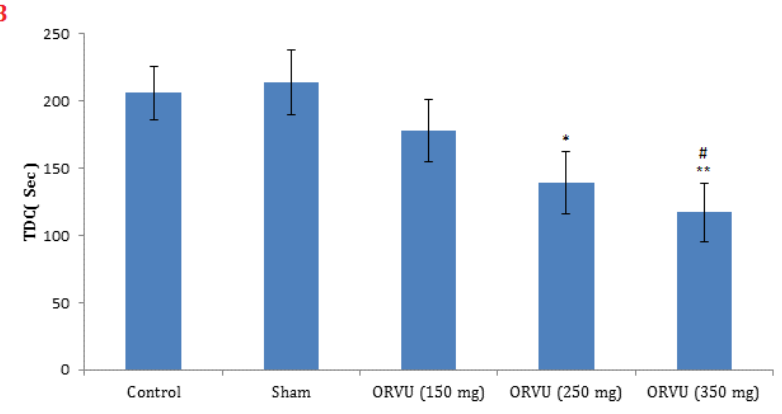

Figure 5. Effects of the aqueous extract of Origanum vulgare (ORVU) on the step-through latency (STLr) (A) and the time spent in the dark compartment (TDC) (B) in the retention test. Each column and bar represents the mean \pm SEM. ${ }^{*} P<0.05$ and ${ }^{* *} P<0.01$ compared with the control group; \#P $<0.05$ compared with the "O. vulgare (150 mg)" group.

antioxidants can effectively enhance learning and memory (24). Hence, one of the possible mechanisms underlying the improvement effects of $O$. vulgare on learning and memory may be related to its antioxidant properties. It has been shown that some combinations of $O$. vulgare decrease lipid peroxidation in neural cells (14). Rosmarinic acid, eriocitrin, apigenin-7-O-glucoside, ursolic acid, and oreganol $\mathrm{A}$ and $\mathrm{B}$ are the most important bioactive constituents in $O$. vulgare $(14,15)$. Rosmarinic and ursolic acid are the main components of the $O$. vulgare with antioxidative properties. Thus, using O. vulgare may increase the antioxidant capacity of the consumers. In molecular-based studies, ursolic acid and rosmarinic acid are supportive against amyloid-beta (A $\beta)$-induced reactive oxygen species production. Several in vitro studies also have shown that the $A \beta$ protein elevates free radical synthesis and oxidative degradation of lipids in neurons. However, vitamin E pretreatment and using ursolic acid prevented the $\mathrm{A} \beta$-induced neurotoxicity (41).

Another potential mechanism underlying the effectiveness of $O$. vulgare on learning and memory may be related to the increased levels of acetylcholine in the hippocampus following the consumption of O. vulgare, as ursolic acid is known as a potent acetylcholinesterase inhibitor (42). Therefore, the antioxidant and acetylcholinesterase inhibition properties of $O$. vulgare may be involved in the observed effectiveness of $O$. vulgare on learning and memory. 


\section{Conclusion}

In summary, the aqueous extract of $O$. vulgare enhanced learning and memory in rats. Hence, this plant might be useful in patients with Alzheimer's disease. One of the mechanisms underlying the effectiveness of $\mathrm{O}$. vulgare on learning and memory may be related to its antioxidant properties. Further studies are required for a better understanding of the neurobiological effects of $O$. vulgare extract on the cognitive process.

\section{Acknowledgments}

The authors would like to express their gratitude to the staff of the Neurophysiology Research Center for their cooperation to carry out this research.

\section{Authors' contributions}

AK designed, analyzed the data, and revised the manuscript. AG was responsible for performing the experimental procedures. FT and NF provided assistance in the study design. AG and SAK participated in plant extraction and all animal interventions. SAK and SS participated in the draft preparation. The paper was read and approved by all authors.

\section{Conflict of interests}

The authors declare no conflict of interest.

\section{Ethical considerations}

All procedures were approved by the ethics committee of Hamadan University of Medical Sciences (Approval code: IR.UMSHA.REC.1394.305).

\section{Funding/Support}

This research was financially supported by the Hamadan University of Medical Sciences

(Grant No.: 9406313506).

\section{References}

1. Mancini E, Camele I, Elshafie HS, De Martino L, Pellegrino C, Grulova D, et al. Chemical composition and biological activity of the essential oil of Origanum vulgare ssp. hirtum from different areas in the Southern Apennines (Italy). Chem Biodivers. 2014;11(4):639-51. doi: 10.1002/ cbdv.201300326.

2. Kennedy DO, Wightman EL. Herbal extracts and phytochemicals: plant secondary metabolites and the enhancement of human brain function. Adv Nutr. 2011;2(1):32-50. doi: 10.3945/an.110.000117.

3. Kumar AS, Kavimani S, Jayaveera KN. A review on medicinal plants with potential antidiabetic activity. Int J Phytopharmacol. 2011;2(2):53-60.

4. Kintzios SE. Oregano: The Genera Origanum and Lippia. London: CRC press; 2003.

5. Yin H, Fretté XC, Christensen LP, Grevsen K. Chitosan oligosaccharides promote the content of polyphenols in Greek oregano (Origanum vulgare ssp. hirtum). J Agric Food Chem. 2012;60(1):136-43. doi: 10.1021/jf204376j.
6. Lemhadri A, Zeggwagh NA, Maghrani M, Jouad H, Eddouks M. Anti-hyperglycaemic activity of the aqueous extract of Origanum vulgare growing wild in Tafilalet region. J Ethnopharmacol. 2004;92(2-3):251-6. doi: 10.1016/j.jep.2004.02.026.

7. Santoyo S, Cavero S, Jaime L, Ibañez E, Señoráns FJ, Reglero G. Supercritical carbon dioxide extraction of compounds with antimicrobial activity from Origanum vulgare L.: determination of optimal extraction parameters. J Food Prot. 2006;69(2):369-75. doi: 10.4315/0362-028x-69.2.369.

8. Exarchou V, Godejohann M, van Beek TA, Gerothanassis IP, Vervoort J. LC-UV-solid-phase extraction-NMR-MS combined with a cryogenic flow probe and its application to the identification of compounds present in Greek oregano. Anal Chem. 2003;75(22):6288-94. doi: 10.1021/ac0347819.

9. Chou TH, Ding HY, Lin RJ, Liang JY, Liang CH. Inhibition of melanogenesis and oxidation by protocatechuic acid from Origanum vulgare (oregano). J Nat Prod. 2010;73(11):176774. doi: $10.1021 / \mathrm{np} 100281 \mathrm{~g}$.

10. Ding HY, Chou TH, Liang CH. Antioxidant and antimelanogenic properties of rosmarinic acid methyl ester from Origanum vulgare. Food Chem. 2010;123(2):254-62. doi: $\quad 10.1016 /$ j.foodchem.2010.04.025.

11. Liang $\mathrm{CH}$, Chan LP, Ding HY, So EC, Lin RJ, Wang HM, et al. Free radical scavenging activity of 4-(3,4-dihydroxybenzoyloxymethyl)phenyl-O-betaD-glucopyranoside from Origanum vulgare and its protection against oxidative damage. J Agric Food Chem. 2012;60(31):7690-6. doi: 10.1021/jf302329m.

12. Saxena M, Saxena J, Pradhan A. Flavonoids and phenolic acids as antioxidants in plants and human health. Int J Pharm Sci Rev Res. 2012;16(2):130-4.

13. Kintzios S, Papageorgiou K, Yiakoumettis I, Baricevic D, Kusar A. Evaluation of the antioxidants activities of four Slovene medicinal plant species by traditional and novel biosensory assays. J Pharm Biomed Anal. 2010;53(3):773-6. doi: $10.1016 /$ j.jpba.2010.05.013.

14. Matsuura H, Chiji H, Asakawa C, Amano M, Yoshihara T, Mizutani J. DPPH radical scavengers from dried leaves of oregano (Origanum vulgare). Biosci Biotechnol Biochem. 2003;67(11):2311-6. doi: 10.1271/bbb.67.2311.

15. Kulisić T, Krisko A, Dragović-Uzelac V, Milos M, Pifat G. The effects of essential oils and aqueous tea infusions of oregano (Origanum vulgare L. spp. hirtum), thyme (Thymus vulgaris L.) and wild thyme (Thymus serpyllum L.) on the copper-induced oxidation of human low-density lipoproteins. Int J Food Sci Nutr. 2007;58(2):87-93. doi: 10.1080/09637480601108307.

16. Lee JL. Memory reconsolidation mediates the strengthening of memories by additional learning. Nat Neurosci. 2008;11(11):1264-6. doi: 10.1038/nn.2205.

17. Berman DE, Dudai Y.Memory extinction, learning anew, and learning the new: dissociations in the molecular machinery of learning in cortex. Science. 2001;291(5512):2417-9. doi: 10.1126/science.1058165.

18. Sharifzadeh M, Sharifzadeh K, Naghdi N, Ghahremani $\mathrm{MH}$, Roghani A. Posttraining intrahippocampal infusion of a protein kinase aII inhibitor impairs spatial memory retention in rats. J Neurosci Res. 2005;79(3):392-400. doi: 10.1002/jnr.20358. 
19. Pahlavan Y, Sepehri G, Sheibani V, Afarinesh Khaki M, Gojazadeh M, Pahlavan B, et al. Study the antinociceptive effect of intracerebroventricular injection of aqueous extract of Origanum vulgare leaves in rat: possible involvement of opioid system. Iran J Basic Med Sci. 2013;16(10):1109-13.

20. Cohen RM, Rezai-Zadeh K, Weitz TM, Rentsendorj A, Gate D, Spivak I, et al. A transgenic Alzheimer rat with plaques, tau pathology, behavioral impairment, oligomeric abeta, and frank neuronal loss. J Neurosci. 2013;33(15):6245-56. doi: 10.1523/jneurosci.3672-12.2013.

21. Baharlouei N, Sarihi A, Komaki A, Shahidi S, Haghparast A. Blockage of acquisition and expression of morphineinduced conditioned place preference in rats due to activation of glutamate receptors type II/III in nucleus accumbens. Pharmacol Biochem Behav. 2015;135:192-8. doi: $\quad 10.1016 / j . p b b .2015 .06 .004$.

22. Komatsu T, Chiba T, Yamaza H, Yamashita K, Shimada A, Hoshiyama $\mathrm{Y}$, et al. Manipulation of caloric content but not diet composition, attenuates the deficit in learning and memory of senescence-accelerated mouse strain P8. Exp Gerontol. 2008;43(4):339-46. doi: 10.1016/j. exger.2008.01.008.

23. Kohara Y, Kuwahara R, Kawaguchi S, Jojima T, Yamashita K. Perinatal exposure to genistein, a soy phytoestrogen, improves spatial learning and memory but impairs passive avoidance learning and memory in offspring. Physiol Behav. 2014;130:40-6. doi: 10.1016/j.physbeh.2014.03.006.

24. Komaki A, Karimi SA, Salehi I, Sarihi A, Shahidi S, Zarei $M$. The treatment combination of vitamins $\mathrm{E}$ and $\mathrm{C}$ and astaxanthin prevents high-fat diet induced memory deficits in rats. Pharmacol Biochem Behav. 2015;131:98-103. doi: 10.1016/j.pbb.2015.02.008.

25. Khodamoradi N, Komaki A, Salehi I, Shahidi S, Sarihi A. Effect of vitamin E on lead exposure-induced learning and memory impairment in rats. Physiol Behav. 2015;144:90-4. doi: 10.1016/j.physbeh.2015.03.015.

26. Barzegar S, Komaki A, Shahidi S, Sarihi A, Mirazi N, Salehi I. Effects of cannabinoid and glutamate receptor antagonists and their interactions on learning and memory in male rats. Pharmacol Biochem Behav. 2015;131:87-90. doi: 10.1016/j. pbb.2015.02.005.

27. Asadbegi M, Yaghmaei P, Salehi I, Komaki A, EbrahimHabibi A. Investigation of thymol effect on learning and memory impairment induced by intrahippocampal injection of amyloid beta peptide in high fat diet- fed rats. Metab Brain Dis. 2017;32(3):827-39. doi: 10.1007/s11011017-9960-0.

28. Zarrinkalam E, Ranjbar K, Salehi I, Kheiripour N, Komaki A. Resistance training and hawthorn extract ameliorate cognitive deficits in streptozotocin-induced diabetic rats. Biomed Pharmacother. 2018;97:503-10. doi: 10.1016/j. biopha.2017.10.138.

29. Moradkhani S, Salehi I, Abdolmaleki S, Komaki A. Effect of Calendula officinalis hydroalcoholic extract on passive avoidance learning and memory in streptozotocininduced diabetic rats. Anc Sci Life. 2015;34(3):156-61. doi: 10.4103/0257-7941.157160.

30. Zarrinkalam E, Heidarianpour A, Salehi I, Ranjbar K,
Komaki A. Effects of endurance, resistance, and concurrent exercise on learning and memory after morphine withdrawal in rats. Life Sci. 2016;157:19-24. doi: 10.1016/j. lfs.2016.05.034.

31. Tamburella A, Micale V, Mazzola C, Salomone S, Drago F. The selective norepinephrine reuptake inhibitor atomoxetine counteracts behavioral impairments in trimethyltin-intoxicated rats. Eur J Pharmacol. 2012;683(13):148-54. doi: 10.1016/j.ejphar.2012.02.045.

32. Ghavipanjeh GR, Alaei H, Khazaei M, Pourshanazari AA, Hoveida R. Effect of acute and chronic hypertension on short- and long-term spatial and avoidance memory in male rats. Pathophysiology. 2010;17(1):39-44. doi: 10.1016/j.pathophys.2009.07.002.

33. Kucukatay V, Ağar A, Gumuslu S, Yargiçoğlu P. Effect of sulfur dioxide on active and passive avoidance in experimental diabetes mellitus: relation to oxidant stress and antioxidant enzymes. Int J Neurosci. 2007;117(8):1091107. doi: 10.1080/00207450600934531.

34. Stranahan AM, Arumugam TV, Cutler RG, Lee K, Egan JM, Mattson MP. Diabetes impairs hippocampal function through glucocorticoid-mediated effects on new and mature neurons. Nat Neurosci. 2008;11(3):309-17. doi: $10.1038 / \mathrm{nn} 2055$.

35. Baradaran A, Rabiei Z, Rafieian M, Shirzad H. A review study on medicinal plants affecting amnesia through cholinergic system. J Herbmed Pharmacol. 2012;1(1):3-9.

36. Bahmani M, Rafieian M, Baradaran A, Rafieian S, RafieianKopaei M. Nephrotoxicity and hepatotoxicity evaluation of Crocus sativus stigmas in neonates of nursing mice. J Nephropathol. 2014;3(2):81-5. doi: 10.12860/jnp.2014.16.

37. Nikfarjam $M$, Bahmani $M$, Naimi A. Native medicinal plants of Iran effective on memory and learning: a review. Int J PharmTech Res. 2016;9(5):466-73.

38. Sheibani V, Afarinesh M, Hajializadeh Z, Abbasnejad M, Haghpanah T, Arabnezhad R, et al. Evaluation of Origanum vulgare L. ssp. viridis leaves extract effect on discrimination learning and LTP induction in the CA1 region of the rat hippocampus. Iran J Basic Med Sci. 2011;14(2):177-84. doi: 10.22038/ijbms.2011.4984.

39. Haghpanah T, Esmailpour Bezanjani K, Afarinesh Khaki MR, Sheibani V, Abbasnejad M, Masoomi Ardakani Y. Effect of intra-hippocampal injection of Origanum vulgare L. ssp. viridis leaf extract on spatial learning and memory consolidation. Feyz. 2011;14(4):380-7. [Persian].

40. Fukui K, Onodera K, Shinkai T, Suzuki S, Urano S. Impairment of learning and memory in rats caused by oxidative stress and aging, and changes in antioxidative defense systems. Ann N Y Acad Sci. 2001;928:168-75. doi: 10.1111/j.1749-6632.2001.tb05646.x.

41. Heo HJ, Cho HY, Hong B, Kim HK, Heo TR, Kim EK, et al. Ursolic acid of Origanum majorana L. reduces Abetainduced oxidative injury. Mol Cells. 2002;13(1):5-11.

42. Vági E, Rapavi E, Hadolin M, Vásárhelyiné Perédi K, Balázs A, Blázovics A, et al. Phenolic and triterpenoid antioxidants from Origanum majorana L. herb and extracts obtained with different solvents. J Agric Food Chem. 2005;53(1):1721. doi: $10.1021 /$ jf048777p. 